\title{
Artelogie
}

Recherche sur les arts, le patrimoine et la littérature de l'Amérique latine

$7 \mid 2015$

Photographie contemporaine en Amérique latine

\section{Photographie contemporaine en Amérique latine}

\section{Charles Monteiro et Gonzalo Leiva Quijada}

\section{OpenEdition \\ Journals}

Édition électronique

URL : https://journals.openedition.org/artelogie/1057

DOI : 10.4000/artelogie.1057

ISSN : 2115-6395

Traduction(s) :

Fotografia na América Latina Contemporânea - URL : https://journals.openedition.org/artelogie/1059 [pt]

Fotografía en América Latina Contemporánea - URL : https://journals.openedition.org/artelogie/1432 [es]

Éditeur

Association ESCAL

Référence électronique

Charles Monteiro et Gonzalo Leiva Quijada, «Photographie contemporaine en Amérique latine », Artelogie [En ligne], 7 | 2015, mis en ligne le 15 avril 2015, consulté le 11 avril 2022. URL : http:// journals.openedition.org/artelogie/1057 ; DOI : https://doi.org/10.4000/artelogie.1057

Ce document a été généré automatiquement le 11 avril 2022

Association ESCAL 


\title{
Photographie contemporaine en Amérique latine
}

\author{
Charles Monteiro et Gonzalo Leiva Quijada
}

1 Le dossier sur la photographie contemporaine latino-américaine comporte trois axes qui constituent des voies pour redéfinir la photographie latino-américaine comme centre opérationnel de l'appropriation et de l'originalité créative. La transdiciplinarité est une clef épistémologique, ouvrant sur un territoire géographique et mental mais aussi sur des systèmes de représentation métis, qui révèle la richesse, la vitalité et la multiplicité des recherches en cours sur la photographie en Amérique Latine.

2 Les différentes approches et les perspectives théoriques sont placées dans un contexte géographique large (Argentine, Brésil, Chili, Colombie, Mexique, Uruguay, Venezuela) et un arc de temps allant de la seconde moitié du xIx siècle au $\mathrm{xxI}^{\mathrm{e}}$ siècle. Les problématiques proposées dans l'appel à projet ont abouti à des contributions théoriques et méthodologiques interdisciplinaires sur la photographie, en dialogue avec les champs de l'histoire de l'art, l'esthétique, l'histoire et l'anthropologie ainsi qu'avec les études visuelles. Le corps, le paysage, les identités, les différents points de vue sur les peuples autochtones, les conflits politiques dans le développement de l'imaginaire national et l'invention des images du pouvoir, sont autant de sujets abordés dans les articles.

3 Les auteurs ont pleinement répondu au défi lancé par les organisateurs sur le regard et la vision, comme des constructions sociales, culturelles, artistiques et scientifiques. Ils ont été amenés à réfléchir sur les circuits de production et de circulation aussi bien que sur les usages sociaux d'images photographiques, afin de comprendre la fabrique imaginaire des représentations sociales et les significations en litiges. Le dossier s'organise en trois thématiques principales : Mémoires et imaginaires, Esthétique et anthropologies, et enfin Pratiques et langues photographiques. 


\section{AUTEURS}

CHARLES MONTEIRO

PUC-RSBrasil

GONZALO LEIVA QUIJADA

PUC-Chile 